\title{
A Study on Teaching Method of Combining Field Experiment with Classroom Teaching in the Course of Economics
}

\author{
Yaping Jiang \\ Shanghai Normal University Tianhua College, \\ Shanghai, 201815 \\ 260224960@qq.com
}

\begin{abstract}
Such a research method as field experiment is playing an increasing predominant role in the study of economics theories. With the improvement of the level of economics research and the modernization of research tools, new standards and new tools are urgently brought forward for the need of economics classroom teaching. This paper attempts to introduce field experiment into the classroom teaching of economics, and guides students to verify the principles of economics with facts and evidence, so as to improve their learning effect.
\end{abstract}

Keywords-Economics; Classroom Teaching; Field Experiment

\section{INTRODUCTION}

In higher education teaching, it is generally believed that only students who major in science and engineering are likely to do experiments, through which they can learn, master and apply theoretical knowledge into practice. As a matter of fact, such liberal subjects as Economics also require experimental teaching. Nowadays, more and more economists have realized the value of experiments, who begin to solve economic problems with experimental methods applied in the field of natural science. Correspondingly speaking, more and more teachers have introduced experimental teaching method into the course of Economics. For example, in the teaching of the Principles of Macroeconomics, students are required to obtain indirect data through economic bulletins publicly issued, statistical yearbooks and other means for verification in the completion of experimental tasks. This experimental method however has a limited fact that students merely need to verify the existing phenomenon in the laboratory according to the description of the teacher, which is not conducive to mobilizing students' enthusiasm to participate in social practice. That fact results in students' lack of enthusiasm to further explore an unknown world. Therefore, this paper suggests that teachers should carry out field experiments in the classroom teaching of Economics in order to develop better methods of experimental teaching.

\section{THE CONCEPT, CHARACTERISTICS AND APPLICATION OF FIELD EXPERIMENT}

\section{A. Selecting The Concept of Field Experiment}

At present, the "experiment" conducted by the academia circle mainly include three types such as traditional laboratory experiment, field experiment and survey experiment. Among them, field experiment is an experimental investigation conducted by experimenters as a treatment for human intervention on research objects. It is very different from traditional laboratory experiment and survey experiment carried out by means of telephone visit, Internet or face-to-face interview. It is conducted in the living environment of the observed subjects. Specifically designed, experimenters are able to intervene or impact the thought and behavior of the observed in a certain way, so as to observe corresponding changes in the values of other items and verify the causal relations between variables. [1]

\section{B. The Characteristics of Field Experiment}

Compared with laboratory experiment, field experiment is closer to the real world. For example, field experiment is conducted in the field rather than in the laboratory not randomly being investigated. That being said, it prefers real objects to induced valuation. In addition, field experiment is more likely to set real situations rather than abstract terms in their descriptions.[2] Specifically speaking, field experiment is more realistic, targeted and extensive than laboratory experiments. It is mainly reflected in the following aspects: (1) research subjects in field experiment are mainly college students, workshop workers, vegetable vendors, enterprise managers, farmers, etc. (2) the real situations embedded in the experiment design are not closed laboratories but mostly scenes and environments in daily life.

\section{The Application of Field Experiment}

Field experiment is a crucial research method in social science research. Although it started late, it has been universally acknowledged in all kinds of research fields abroad such as economics, sociology and political science. Based on that fact, this paper draws a conclusion on the typical application examples of this method in the field of economics 
research, and then provides some ideas and methods for carrying out field experiment in the teaching of Economics.

Field experiment is widely applied in economic research and has achieved fruitful results. A study made by Soetevent (2005) [3] shows that how does the anonym donation in the churches impact on the donation behavior of research subjects. He designed two different containers for collecting donations, one sealed for the control group and another open and transparent for the treatment group. Both of them differ in a fact that if the donation container is open and transparent, the donors are able to clearly observe the amount of contributions from other donors, and they can also see the amount of donations already in the collection container when making a donation. Sealed donation containers do the opposite. Soetevent's study shows that the amount of donations raised will increase significantly when the donation container is open and transparent. Another field experiment research is conducted by Cohen and Dupas (2010) [4] in Kenya to provide insecticide-resistant mosquito nets. In this study, they randomly selected 20 clinics to provide mosquito nets, four of which were control groups and the rest 16 of which were provided with mosquito nets at random into four price levels ranging from free to 40 shillings (Kenyan currency, it is equivalent to $\$ 0.60$ dollar). In order to find out whether pregnant women who need bed nets most are willing to pay for, researchers tested the heme level of all pregnant women for their healthcare situation. In addition, they visited back all pregnant families at home months after the nets have been distributed in order to see whether they were being used. According to this study, it is concluded that there is no significant drop in demand when the price increased from 0 to $\$ 0.15$ dollar, while there is about 60 percent of decline in demand when the price increased to \$0.6 dollar. There was no evidence that its willingness to pay for a bed net is correlated with the demands of pregnant families. As a result, those pregnant women giving the highest bidder actually used the net more than those who received it for free. On the other hand, those who got it at the median price levels used it less. That being said, there is no evidence that the price of mosquito nets will have a critical impact on the purchasing willingness of women who need bed nets more whether mosquito nets are for free assistance or costsharing. According to the heme test, it is found that women who were willing to pay more for were seldom weaker than those in the control groups. Therefore, based on needs and elastic parameter estimates, researchers combined individual and social returns (infant mortality), it is concluded that free assistance is as economically efficient as cost-sharing. Chetty (2009) [5] had a study on people's decision making of consumption through cooperation with supermarkets. He recorded the sales volume when the price is tagged without tax in the supermarket first, and then recorded the sales volume when he tagged price within taxes. As a consequence, it is shown that although the final amount paid by consumers is the same under the two pricing methods, excluding tax and including tax. Since the price in tagged including tax or the price looked higher at first sight, the sales volume of these goods will decrease significantly. This experimental result confirms that there is an irrational factor influencing consumer on decision-making.
III. Design OF TEAching IdEAS ON TEACHING MEthod OF COMBINING FIELD EXPERIMENT WITH CLASSROOM TEACHING IN THE COURSE OF ECONOMICS

Contemporary college students generally are characterized with the following points: first, they have outstanding personalities; second, they are willing to express themselves; third, they are good at accepting new things; four, they pay closer attention to the practical application based on theoretical study. The traditional method with cramming teaching cannot adapt to the characteristics of contemporary college students. Shanghai Normal University Tianhua College which the author works at has been implementing the construction of "Dynamic Classroom" since 2016, for the promotion of education philosophy with teachers' leading role and students' centerbased role. Under this background, the author applies the third batch of teaching reform pilot course based on "Dynamic Classroom", "The Principles of Economics". During the three years of development, the author makes awareness that if teachers want to make some basic economics theories into students' mind, they would build their own cognitive system. It is suggested that traditional classroom teaching method cannot work efficiently alone. They should let students verify the theory studies through developing experiments in real situation, so as to deepen students' impression for the gradual construction of professional theory system, which can achieve twice the result with half the effort. Based on teaching experience of these years, the author deems that not all the teaching contents of Economics are suitable for carrying out field experiment. As a result, it is more in line with the current teaching practice of Economics to combine some teaching method with field experiment in the course of classroom teaching. The implementation steps are designed as follows:

\section{A. The teacher should explain the basic theory better.}

The experiment is not a castle in the air, but a verification of the basic theory for the specialized course. In view of this, the teacher must explain the basic theory better before the experiment carries out. Only in this way can students have a more comprehensive, systematic understanding and get a preliminary grasp of the theoretical system for the specialized course. This is the foundation for field experiments.

\section{B. Field experiment objects should be selected carefully.}

To do experiments, research objects should be taken into consideration first of all. The experiment objects mainly come from two aspects: one is the student group, which is the most accessible experimental object; another is other organizations or individuals. The teachers must compare the basic theory of Economics, choose the suitable experiment object and design a reasonable experiment plan.

\section{Teachers should make a full preparation for the experiment.}

The teachers should send the experiment plans to the students in advance, which can be used to guide the students to prepare for the field experiment. At the same time, the teachers should let their students master the relevant economic principles of the field experiment well. At the same time, they should let their students use the economic principles mastered 
to conduct a comprehensive and further analysis of the field experiment. In addition, teachers should also train students in language expression and psychological quality, so as to avoid interference with the experimental results caused by language induction.

\section{Field experiment is officially carried out.}

Teachers should first let students well know the purpose, process and matters needing attention during the field experiment. Furthermore, they should assign various roles or diverse groups according to different students, and let students know how to record experimental data that is very critical in the process of field experiments. As the classroom teaching of Economics is usually conducted in the unit of discipline and specialty, students are familiar with each other, which will cause deviation of field experiment hypothesis conditions and thus interfere with experimental results. Therefore, in the process of experiment, teachers should pay more attention to remind students of not informing and communicating.

\section{E. Students should collate and verify data and write experiment reports}

After the completion of field experiments, students are required to check the relevant economic theories, establish econometric models when necessary sort out and verify the data, and independently write field experiment reports.

\section{F. Teachers should organize class discussion and communication.}

In field experiment, the combination of action, observation, listening and thinking, students' awareness of problems, their research awareness and abilities to combine theories with practice have been cultivated and developed better to some extent. However, due to subjective and objective factors, grades are generally uneven among students. Therefore, in order to further improve the comprehensive abilities of all students, after completing the above five steps, teachers should organize students to carry out class discussion and communication. The teacher should first organize the students to conduct the discussion in groups, and then attempt to ask each group for electing a representative to present the core ideas formed by the group discussion in front of the whole class. Finally, the teacher should make a comment on the discussion results for each group.

\section{EXAMPLES OF THE TEACHING SCHEME ON TEACHING METHOD OF COMBINING FIELD EXPERIMENT WITH ClASSROOM TEACHING IN THE COURSE OF ECONOMICS}

\section{A. Field experiment based on "rational-economic man"}

In view of the theoretical hypotheses related to "hypothesis of rational man" in the course of Economics, this paper designs the field experiment based on "hypothesis of rational man" in order to help students determine whether the subjects in the actual economic society are completely rational when making decisions.

The experimental scheme is designed as follows: firstly, teachers should randomly divide students into two groups and give them a letter respectively. "Dear students, millions of children in Africa are suffering from hunger, cold and illness. They are at disease risks in great need for medicine. Please reach out and help them!" Another group received the following letter: "dear students, there is a little girl in Africa. Her name is $\mathrm{xx}$. She lives in $\mathrm{xx}$ town, $\mathrm{xx}$ city and $\mathrm{xx}$ country. Please give her a helping hand!"

As the author has thought, the latter letter received significantly more money than the previous one, even though the former one pointed out that millions of children need help. Therefore, in practice, people's rationality runs between perfect rationality and irrationality. In other words, people are born in bounded rationality.

\section{B. Field experiment based on "the flexibility coefficient of the price"}

In view of the relevant theories of "the flexibility coefficient of the price" in the course of Economics, this paper designs a field experiment to calculate the flexibility coefficient, so that students can verify the price flexibility of demand for various commodities in daily life and the factors affecting price flexibility.

The experimental scheme is planned as follows: students are randomly divided into groups each with two persons. Students are required to enter the vegetable farm to choose a commodity. They can be allowed to choose any goods such as vegetables, meat, poultry, aquatic products, eggs, etc. Through field observation and personal interviews, students should write down and collect the daily price and sales data of the selected commodity. The time span is three months. After that experiment, the flexibility coefficient of selected goods is calculated and verified by using the calculation formula of the flexibility coefficient of demand price. As a result, it can make a systematic discussion on the impact of demand degree, substitution degree and other factors on the flexibility of goods.

\section{Field experiment based on the charm of free trade}

In terms of the relevant content of "market economy" in the course of economic principles, field experiment based on "the charm of free trade" can be designed to help students well understand the meaning of market economy. In the real world, resources are scarce, and thus every voluntary transaction means individual life is getting better. In fact, the total amount of resources does not change with personal livelihood. This is the power of the trade.

Experimental scheme is designed as follows: the teacher first collect 20 students as volunteers to take part in the experiment (there are 10 boys and 10 girls). A T-shirt is sent to each student, but every experiment object is given T-shirt with unsuitable size. In this way, then the teacher starts to investigate the satisfaction of students for T-shirt that students got. Secondly, research subjects are allowed to exchange tshirts at their own free wills, but are told that "boys could only trade with boys and girls with girls". Finally, all participants are allowed to trade freely with anyone. Furthermore, after the trade was over, they are again asked how satisfied they were with the T-shirts they had. This experiment aims to see whether the satisfaction of the research subjects is improved by free 
trading when the number of T-shirts remains unchanged and no one in charge assigns them.

\section{CONCLUSION}

The Principles of Economics is a subject closely combined with practice, which requires teachers to pay closer attention to the cultivation of students' application abilities in teaching practice, especially for the independent colleges aiming at cultivating application-oriented talents. The field experiment is introduced in order to provide new ideas and approaches for the course reform of the Principles of Economics. Certainly, there is no a perfect teaching method. There are some limitations and deficiencies in carrying out field experiment in the classroom teaching of the Principles of Economics. Such as great manpower, the material resources and the financial resources, requires investing which occupies longer class hours than other teaching methods. However, in general, field experiment can effectively promote the construction of students' professional knowledge system of economics and realize the internalization of knowledge, which is a teaching method worthy of promotion.

\section{REFERENCES}

[1] Han Donglin. Field experiments: concepts, methods and political studies [J]. Foreign Social Sciences, 2018(1):134-142.(In Chinese)

[2] Luo Jun. Field Experiments - Economic Experiments in the Real World [J]. Southern Economy, 2014 (6): 87-92.(In Chinese)

[3] AR Soetevent. Anonymity in giving in a natural context - a field experiment in 30 churches[J].Journal of Public Economics, 2005.

[4] S DellaVigna, JA List, U Malmendier.Testing for Altruism and Social Pressure in Charitable Giving[J].The Quarterly Journal of Economics, 2012.

[5] JP Carpente, SV Burks, EA Verhoogen.Comparing Students to Workers:The Effects of Social Framing on Behavior in Distribution Games[J].Social Science Electronic Publishing, 2004

[6] J Cohen, P Dupas. Free Distribution or Cost-Sharing? Evidence from a Randomized Malaria Prevention Experiment[J].Social Science Electronic Publishing, 2010.

[7] R Chetty, A Looney, K Kroft. Salience and Taxation: Theory and Evidence[J].American Economic Review, 2009. 